\title{
New avenues for regulation of lipid metabolism by thyroid hormones and analogs
}

\author{
Rosalba Senese, Pasquale Lasala, Cristina Leanza and Pieter de Lange* \\ Dipartimento di Scienze e Tecnologie Ambientali, Biologiche e Farmaceutiche, Seconda Università degli Studi di Napoli, Caserta, Italy
}

\section{Edited by:}

Jean-Pierre Montani, University of

Fribourg, Switzerland

\section{Reviewed by:}

Giovanni Solinas, University of Gothenburg, Sweden

Paul Webb, Houston Methodist

Research Institute, USA

*Correspondence:

Pieter de Lange, Dipartimento di

Scienze e Tecnologie Ambientali,

Biologiche e Farmaceutiche,

Seconda Università degli Studi di

Napoli, Via Vivaldi 43, 1-81100

Caserta, Italy

e-mail: pieter.delange@unina2.it
Weight loss due to negative energy balance is a goal in counteracting obesity and type 2 diabetes mellitus. The thyroid is known to be an important regulator of energy metabolism through the action of thyroid hormones (THs). The classic, active $\mathrm{TH}$, 3,5,3'-triiodo-L-thyronine (T3) acts predominantly by binding to nuclear receptors termed $\mathrm{TH}$ receptors (TRs), that recognize $\mathrm{TH}$ response elements (TREs) on the DNA, and so regulate transcription. T3 also acts through "non-genomic" pathways that do not necessarily involve TRs. Lipid-lowering therapies have been suggested to have potential benefits, however, the establishment of comprehensive therapeutic strategies is still awaited. One drawback of using T3 in counteracting obesity has been the occurrence of heart rhythm disturbances. These are mediated through one TR, termed TR $\alpha$. The end of the previous century saw the exploration of TH mimetics that specifically bind to TR beta in order to prevent cardiac disturbances, and TH derivatives such as 3,5-diiodo-L-thyronine (T2), that possess interesting biological activities. Several TH derivatives and functional analogs have low affinity for the TRs, and are suggested to act predominantly through non-genomic pathways. All this has opened new perspectives in thyroid physiology and $\mathrm{TH}$ derivative usage as anti-obesity therapies. This review addresses the pros and cons of these compounds, in light of their effects on energy balance regulation and on lipid/cholesterol metabolism.

Keywords: thyroid hormones, lipid metabolism, energy balance, insulin resistance development, obesity

\section{INTRODUCTION}

The thyroid plays a crucial role in the control of energy metabolism through action of thyroid hormones (THs) in metabolically active tissues such as liver, skeletal muscle and brown adipose tissue. Knowledge on TH action has increased significantly after the cloning of the TH receptors (TRs) termed TR $\alpha$ (including splice-variants $\alpha 1$ and $\alpha 2$ of which $\alpha 2$ does not bind to TH) and TR (including transcripts $\beta 1$ and $\beta 2$, with $\beta 1$ predominantly involved in metabolic control, see for a more detailed review: Mullur et al., 2014). TR $\alpha 1$ (henceforth: TR $\alpha$ ) is expressed in the brain and to a lesser extent in kidney, skeletal muscle, lungs, heart, and liver, whereas TR $\beta 1$ (henceforth: $\operatorname{TR} \beta$ ) is expressed predominantly in the kidneys and liver, and at lower levels in brain, heart, thyroid, skeletal muscle, lungs, and spleen (Williams, 2000). In absence of hormone, transcriptional regulation through the TRs is blocked through association with co-repressors (Astapova and Hollenberg, 2013). An example comes from a recent study reporting expression of an inactive mutant of nuclear receptor co-repressor (NCoR), NCoR $\Delta \mathrm{ID}$, in mouse liver which, by favoring coactivator recruitment and receptor activation, resulted in increased expression of genes encoding enzymes involved in bile acid metabolism that are under transcriptional control of TR $\beta$ (Astapova et al., 2014). Interestingly, one coactivator of TR $\beta$ has been recently discovered to be a sirtuin, namely SIRT1 (Singh et al., 2013; Suh et al., 2013; Thakran et al., 2013). To exert their action, TRs commonly heterodimerize with the retinoic X receptor (RXR) but may also homodimerize (Forman et al., 1992). In addition, TRs interact with other nuclear receptors including peroxisome proliferator activated receptors (PPARs), (Bogazzi et al., 1994; Buroker et al., 2007; de Lange et al., 2007). TR-PPAR interactions are of particular importance in regulation of lipid metabolism. The in vivo association of unliganded TR $\alpha$ with PPAR $\alpha$ has been shown to inhibit PPAR $\alpha$ signaling in the liver, a process abolished by $\mathrm{T} 3$ (Liu et al., 2007). A dominant negative TR $\alpha$ mutant associated with PPAR $\alpha$ in a way that could not be abolished by T3, resulting in hepatic steatosis (Liu et al., 2007). Thus, these results imply that T3 "unblocks" PPAR $\alpha$ action by relieving TR $\alpha$ association with PPAR $\alpha$. In accordance, TR $\alpha$ knock-out mice were shown to be protected from diet-induced hepatic insulin resistance (Jornayvaz et al., 2012). TR $\beta$ isoforms reduce serum lipids in vivo (Johansson et al., 2005; Angelin and Rudling, 2010; Pramfalk et al., 2011; Shoemaker et al., 2012). TR $\beta$ disruption in mice has been shown to impair fatty acid oxidation (Araki et al., 2009) which persisted with TR $\alpha$ overexpression (Gullberg et al., 2000, 2002). This implies that $\mathrm{T} 3$ increases lipid metabolism both by binding to $\operatorname{TR} \alpha$ and TR $\beta$ and through PPARs, however through different underlying mechanisms. Physical interactions between TR $\beta$ and PPAR $\alpha$ in mouse heart (Buroker et al., 2007), and PPAR $\delta$ in rat skeletal muscle (de Lange et al., 2007) have been suggested to increase expression of common target genes involved in lipid metabolism. 


\section{THE DEVELOPMENT OF SPECIFIC TR $\beta$ AGONISTS AS LIPID/CHOLESTEROL-LOWERING AGENTS}

Hyperthyroidism can lead to thyrotoxicosis, with increased heart rate, atrial arrhythmias and heart failure, muscle wasting, postmenopausal osteoporosis in women, fatigue, anxiety, and preference for decreased temperatures (Webb, 2004). Basic studies have revealed that $\mathrm{TR} \alpha$ is responsible for TH's effects on heart rate: mice lacking $\mathrm{TR} \alpha$ showed reduced heart rate and body temperature (Wikström et al., 1998), and echocardiograph studies in mice deficient in TR $\alpha$ or TR $\beta$ have revealed that the effects of THs on heart rate are TR $\alpha$-dependent (Weiss et al., 2002). Cardiac contractile functions and the expression of genes involved therein have been shown to be all TR $\alpha$-dependent (Gloss et al., 2001).

Initial studies on $\mathrm{TH}$ analogs date from before the cloning of the TRs and showed that analogs binding strongly to hepatic TRs but weakly to heart TRs (Ichikawa et al., 2000) were effective in reducing body weight and serum lipid/cholesterol levels but did not cause evident cardiac arrhythmias. L-94901, the first described selective thyromimetic compound with $50 \%$ of the binding affinity of T3 to hepatic TRs and only a minimal affinity to cardiac TRs (Underwood et al., 1986), has been reported to lower plasma cholesterol in experimental animals without inducing cardiotoxic side effects. A subsequent compound, CGS 23425, lowered total serum and LDL cholesterol and increased synthesis of apolipoprotein A1 (APOA1). Indeed, after the cloning of the TRs, CGS 23425 was confirmed to be weakly TR $\beta$-selective (Taylor et al., 1997).

Because of TR $\alpha$-associated unwanted side effects of $\mathrm{TH}$, the nineties saw the development of TR $\beta$-specific ligands [these comprise GC-1 (Chiellini et al., 1998), its derivative GC-24 (Borngraeber et al., 2003), and KB141 (Grover et al., 2005)], or, alternatively, ligands targeted to the liver. The first such cholesterol-reducing compound with high liver specificity was CGH-509A (derived from conjugation of L-T3 and cholic acid). Other drugs developed for targeting to the liver were MB-07811, a prodrug of the active metabolite MB07344 (Erion et al., 2007) and KB-2115 (Berkenstam et al., 2008). Several compounds that were intentionally designed to be liver-specific were subsequently also found to be TR $\beta$-selective, and vice versa. For instance, the selective TR $\beta$-agonist GC-1 has been found to be preferentially taken up by the liver (Baxter and Webb, 2009) and, in turn, MB-07811 resulted to be more than ten-fold $\operatorname{TR} \beta$-selective. TR $\beta$ affinity varies between compounds: GC-1 (Chiellini et al., 1998) has equal $\mathrm{TR} \beta$ affinity with respect to T3, GC-24 (Borngraeber et al., 2003) and MB-07344 (Erion et al., 2007; Fujitaki et al., 2008) have a relative twofold-lower affinity, and KB-141 has a sixfold lower relative affinity (Erion et al., 2007). In addition, the synthetic agonists have different pharmacokinetic and pharmacodynamics properties with respect to T3 (Erion et al., 2007). Finally, effective tissue uptake differs between the compounds, which could be related to their relative affinities for the classic $\mathrm{TH}$ transporters such as monocarboxylate transporter-8 (MCT-8) (Erion et al., 2007).

\section{TH ANALOGS AND CHOLESTEROL METABOLISM}

A large number of $\mathrm{TH}$ analogs ameliorate lipid and lipoprotein metabolism through the lowering of plasma total and LDL cholesterol levels and the stimulation of reverse cholesterol transport
(RCT) in different animal models (Baxter and Webb, 2009; Tancevski et al., 2009; Pramfalk et al., 2011). The LDL cholesterollowering effect exerted by TR $\beta 1$ - and liver-selective thyromimetics such as KB-141, GC-1, KB-2115, MB-07811, T-0681, CGS23425, and DITPA (Underwood et al., 1986; Taylor et al., 1997; Grover et al., 2003, 2004; Erion et al., 2007; Tancevski et al., 2009) is ascribed to increased hepatic LDL clearance via stimulation of LDL receptor (Erion et al., 2007; Tancevski et al., 2009, 2010) and the stimulation of cholesterol 7 alpha-hydroxylase (CYP7A1) expression and activity (Gullberg et al., 2000; Johansson et al., 2005; Erion et al., 2007; Tancevski et al., 2010) enhancing hepatic cholesterol uptake and its conversion into bile acids to be excreted by feces. Moreover, T0681 induces the expression of ABCG5 and ABCG8, a tandem pump promoting the biliary excretion of free cholesterol (Tancevski et al., 2010). Recent mechanistic studies in mice showed the LDL receptor (LDLr) expression to be crucial for the hypocholesterolemic effects of MB-07811 and for T-0681 (Erion et al., 2007; Tancevski et al., 2010) which was not the case for that of T3, GC-1 and KB-2115 (Goldberg et al., 2012; Lin et al., 2012). These data suggest that patients with familial hypercholesterolemia may benefit from a treatment with specific $\mathrm{TH}$ analogs.

\section{TRB AGONISTS AND PREVENTION OF HEPATIC STEATOSIS: SIDE EFFECTS INCLUDING INSULIN RESISTANCE}

At first the use of $\operatorname{TR} \beta$ agonists to ameliorate lipid profiles was considered unfavorable due to their potential causing, in analogy with T3, of adipose lipolysis, and induction of hepatic lipogenesis and thus steatosis. In fact, T3 poorly reduces hepatic steatosis in rodent obesity models (Cable et al., 2009). Genetically obese/diabetic rodent models or models of rodents placed on high-fat diets have increasingly been used to investigate the efficiency of these compounds to lower lipid profiles and to counteract non-alcoholic fatty liver disease (NAFLD) (Cable et al., 2009; Vatner et al., 2012) and hepatic insulin resistance (Vatner et al., 2012), with varying outcomes.

MB-07811 efficiently reduced hepatic steatosis as well as plasma FFA and triglycerides in various rodent models including male ob/ob mice, male Zucker diabetic fatty (ZDF) rats, and male $\mathrm{C} 57 \mathrm{Bl} / 6$ mice placed on a high-fat rodent diet $(60 \%$ fat by kcal) for 3 months. This compound, in contrast to T3, did not cause adipose lipolysis, and efficiently reduced hepatic steatosis by inducing hepatic fatty acid oxidation and mitochondrial respiration rates, phenomena known to be related to hepatic TR activation. Unlike T3, MB-07811 did not increase heart weight and neither did it decrease pituitary thyroid-stimulating hormone beta (TSH $\beta$ ) expression (Cable et al., 2009). Additional TR $\beta$ agonists, namely GC- 1 and KB-2115, tested in similar systems have proven to be effective in depleting liver lipids, (Cable et al., 2009; Vatner et al., 2012), but recent evidence has shed doubt on the potential use of these compounds to ameliorate insulin sensitivity (Vatner et al., 2012). Male Sprague-Dawley rats treated daily with GC-1 while being placed on a commercial highfat diet showed a $75 \%$ reduction of hepatic triglyceride content, but developed fasting hyperglycemia and hyperinsulinemia due to increased glucose production and diminished hepatic insulin sensitivity. In addition, white adipose lipolysis was increased, 
which the authors suggest to contribute to endogenous glucose production due to the increased glycerol flux (Vatner et al., 2012). Rats being fed the same diet period but treated daily with KB-2115 displayed a reduction of hepatic steatosis without evident fasting hyperglycemia, increased glucose production or diminished hepatic insulin sensitivity. Instead, insulin-stimulated muscle glucose uptake was diminished with concomitant reductions in glucose transporter 4 (GLUT4) protein content (Vatner et al., 2012). The induction of insulin resistance at various levels by several $\operatorname{TR} \beta$ agonists may put their therapeutic potential into question. Nevertheless, KB-2115 recently entered phase III clinical trials which were discontinued when cartilage damage was observed in a long-term study on dogs (Sjouke et al., 2014).

Despite these drawbacks, the need to develop agents that counteract dyslipidemia persists, thus the search for effective TR $\beta$ agonists remains justified. An overview of the metabolic effects of the described compounds is given in Table 1 .

\section{ACTION OF T3 AND OTHER TH METABOLITES BY NOT DIRECTLY INTERACTING WITH NUCLEAR TR-TRES}

In recent years, it has become ever more clear that $\mathrm{T} 3$ exerts its effects not only through nuclear TR-TRE interactions, but also through cytosolic TRs or even independent of TRs. Ten percent of the TR pool is localized within the cystosol (Baumann et al., 2001) and T3 has been shown to interact with these cytosolic TRs to influence phosphatidyl inositol 3- kinase (PI3K)-Akt signaling, with phosphorylated Akt subsequently influencing transcription of genes involved in glucose metabolism via mammalian target of rapamycin (mTOR) (Moeller et al., 2006). T3-induced phosphorylation of Akt in rat skeletal muscle causes glucose transporter 4 (GLUT4) translocation to the sarcolemma (de Lange et al., 2008). Truncated forms of TRs are also present in mitochondria. A variant of TR $\alpha$ in mitochondria (Wrutniak-Cabello et al., 2001) has been suggested to directly stimulate oxidative phosphorylation upon interaction with T3 (Oetting and Yen, 2007).

Other receptors have been shown to interact with T3: (Davis et al., 2005). TH interacts with integrin alpha $\mathrm{V}$ beta 3 in the cell membrane. This event triggers the MAPK/ERK pathway with phosphorylated MAPK translocating into the nucleus and associating with TR $\beta$ (Plow et al., 2000). This causes phosphorylation of the $\operatorname{TR} \beta$ receptor, enhancing its action on transcription rate (Davis et al., 2000). Thus, TR activation can be enhanced through pathways other than solely TH binding.

Furthermore, T3 causes activation of non-receptor proteins. AMP-activated kinase (AMPK), which plays a central role in lipid and glucose metabolism homeostasis (Hardie et al., 2012), has been shown to be a target of transient and rapid activation (within hours) by T3 in skeletal muscle (de Lange et al., 2008; Irrcher et al., 2008). Sirtuins are NAD+ activated deacetylases that have been shown to play a role in metabolic homeostasis (Chang and Guarente, 2014). T3 has been shown to activate SIRT1 by various groups, and this depends on interaction with TR $\beta$ (Singh et al., 2013; Suh et al., 2013; Thakran et al., 2013). Some effects of T3 through SIRT1 require binding of TR $\beta$ to TREs (Suh et al., 2013;

Table 1 | From thyromimetics to TR $\beta$ ligands and TH metabolites: reported TR $\beta$ affinities and metabolic effects.

\begin{tabular}{|c|c|c|c|c|c|c|}
\hline Ligand & $\begin{array}{l}\text { Displays TR } \beta \text { binding } \\
\text { affinity } \\
\text { (with respect to T3) }\end{array}$ & $\begin{array}{l}\text { Reduces Plasma } \\
\text { LDL cholesterol }\end{array}$ & $\begin{array}{l}\text { Acts LDL receptor- } \\
\text { dependent }\end{array}$ & $\begin{array}{l}\text { Prevents hepatic } \\
\text { steatosis }\end{array}$ & $\begin{array}{l}\text { Causes insulin } \\
\text { resistance }\end{array}$ & $\begin{array}{l}\text { Increases heart } \\
\text { weight/rate }\end{array}$ \\
\hline \multicolumn{7}{|c|}{ THYROMIMETIC } \\
\hline L-94901 & Weak & Yes & & & & No \\
\hline CGS-23425 & Weak & Yes & & & & No \\
\hline \multicolumn{7}{|c|}{ TR $\beta$ AGONIST } \\
\hline GC-1 & Equal & Yes & No & Yes & Yes & No \\
\hline GC-24 & 2-fold lower & Yes & Yes & Yes & & No \\
\hline KB-141 & 6-fold lower & Yes & Yes & & & No \\
\hline T-0681 & & Yes & Yes & & & No \\
\hline DITPA & & Yes & Yes & & & No \\
\hline \multicolumn{7}{|c|}{ LIVER-TARGETED } \\
\hline CGH-509A & & Yes & & & & No \\
\hline MB-07811 & & Yes & & Yes & & No \\
\hline MB-07344 & 2-fold lower & Yes & & Yes & & No \\
\hline KB-2115 & & Yes & No & & Yes & No \\
\hline \multicolumn{7}{|c|}{ TH METABOLITE } \\
\hline TRIAC & $\begin{array}{l}\text { 3-fold higher however } \\
\text { no (or weak) TR } \beta \\
\text { specificity }\end{array}$ & & & & & No \\
\hline T1AM & None & No & No & & Yes & No \\
\hline $\mathrm{T} 2$ & $\begin{array}{l}\text { 60-fold lower } \\
\text { (human TR } \beta \text { ) with no } \\
\text { TR } \beta \text { specificity }\end{array}$ & Yes & No & Yes & $\begin{array}{l}\text { No (rats) } \\
\text { ND (mice) }\end{array}$ & $\begin{array}{l}\text { No/No } \\
\text { (rats) } \\
\text { Yes/ND (mice)* }\end{array}$ \\
\hline
\end{tabular}

Abbreviations: ND, not determined; * dose of T2 used in mice is 10-fold higher. 
Thakran et al., 2013). However, one target of T3-TR $\beta$-SIRT1 action is FOXO1, which upon deacetylation triggers the expression of genes involved in gluconeogenesis in mice that do not necessarily contain a TRE in their promoters (Singh et al., 2013). Some of the above mentioned mechanisms of action exerted by $\mathrm{T} 3$ are shared by other TH metabolites. AMPK activation in skeletal muscle has been found also to occur by 3,5-diiodo-L-thyronine (T2) (Lombardi et al., 2009), as well as SIRT1 activation in liver (de Lange et al., 2011) and in kidney (Shang et al., 2013). These results have added to the realization that some of the actions of T3 (including those on energy metabolism) can overlap with those of the TH metabolites with low affinity for TRs. The mechanistic aspects of the metabolic effects of the thyroid hormone analogs and metabolites are highlighted in Figure 1.

\section{NATURAL TH METABOLITES, PROMISING LIPID-REDUCING AGENTS?}

Besides T3, the thyroid is a source of other iodothyronines, which are either produced within the thyroid itself or are deiodinated periferically, the so-called "non-classical" THs (see for an more extensive overview Senese et al., 2014). One non-classical TH with high TR affinity, Triac (3,5,3'-triiodothyroacetic acid), has been shown to be weakly TR $\beta$-selective and to lower cholesterol without reduced effects on heart rate (Moreno et al., 2008). Other TH metabolites, due to their weak binding to TRs, do not predominantly act through binding to nuclear TRs and by modulating TRE-mediated gene transcription. An example is T1AM, an amine present in serum of rodents and humans (Saba et al., 2010; Hoefig et al., 2011), and in rat liver and brain (Saba et al., 2010). T1AM has no affinity for TR $\beta$ and $\operatorname{TR} \alpha$ (Chiellini et al., 1998). T1AM, however, is a potent agonist of trace amine-associated receptor 1 (TAAR1), an orphan $\mathrm{G}$ proteincoupled receptor (GPCR) (Zucchi et al., 2006). Contrary to T3, T1AM does not ameliorate lipid profiles and may cause insulin resistance depending on the dose: intracerebroventricular (icv) injection of T1AM into short-term fasted male mice in a dose of $130 \mathrm{ng} / 100 \mathrm{gBW}$ (Manni et al., 2012) causes hypophagia as well as peripheral effects namely raised plasma glucose levels and reduced peripheral insulin sensitivity despite increased pancreatic insulin production. This would classify this compound as unsuitable for improving metabolic profiles. Another TH metabolite which has been under study in recent years is T2. This compound

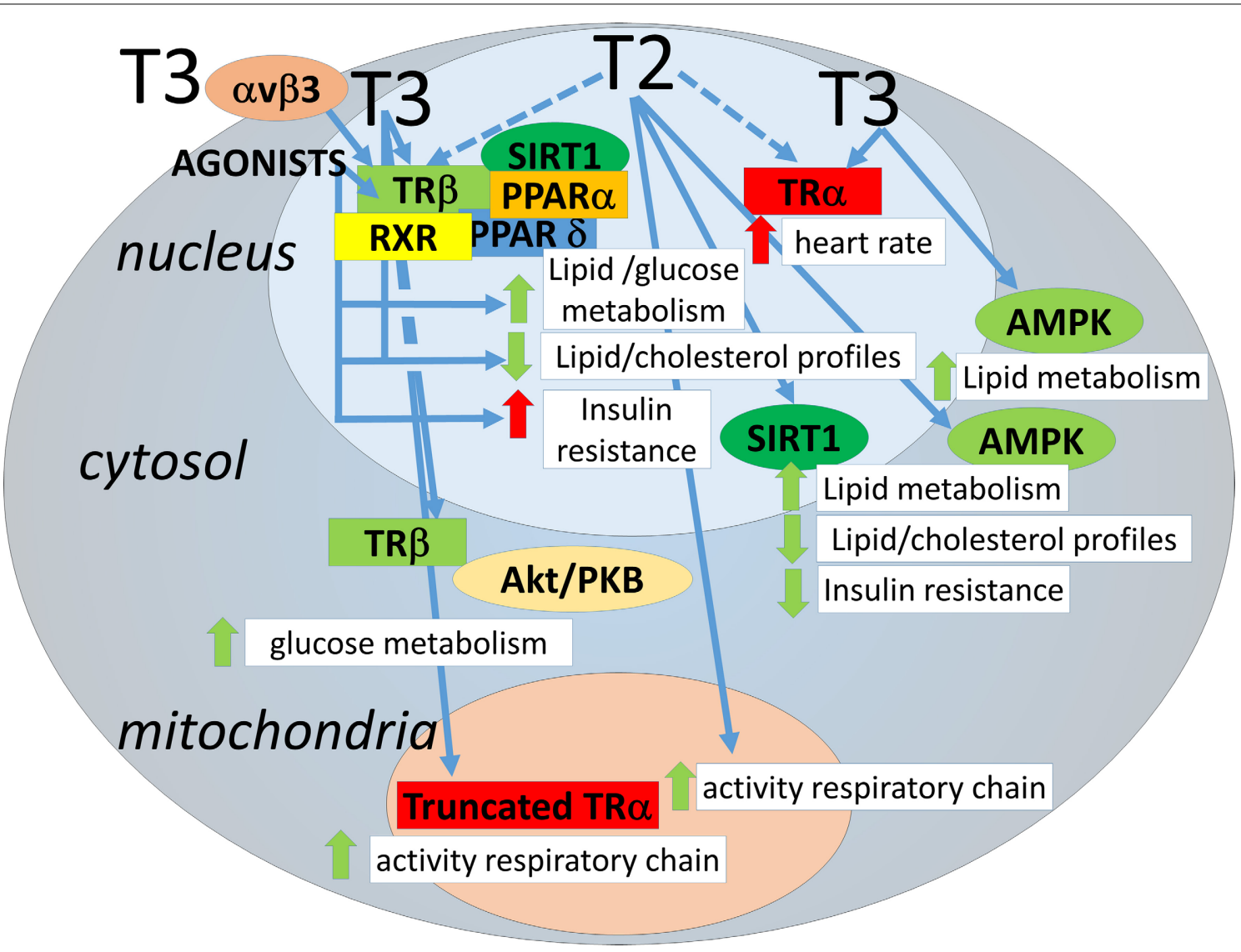

FIGURE 1 | Avenues for regulation of lipid metabolism by thyroid hormones and analogs. THs may act through transcriptional regulation by nuclear TR binding but also through interactions involving cytosolic/mitochondrial TRs or other proteins, each of which influencing lipid metabolism. For clarity, the $\mathrm{TH}$ analogs have not been depicted separately, negative effects on insulin sensitivity have only been demonstrated for a subset (see text). Of the thyroid hormone metabolites only T2 is depicted, since T2 is the only TH metabolite thus far with low affinity for TR $\alpha$ and positive effects on metabolism. Avenues are depicted as blue arrows. Dotted arrows: yet to be determined/confirmed. Effects are depicted as red arrows (negative) or green arrows (positive). 
has a 60 -fold reduced binding capacity to human TR $\beta$ (Mendoza et al., 2013). In line with this, it has been shown that T2 has a weak transactivating capacity of $\operatorname{TR} \beta$ target genes in different systems, in vitro and in vivo (Ball et al., 1997; Cioffi et al., 2010; de Lange et al., 2011; Mendoza et al., 2013). Interestingly, $\mathrm{T} 2$ has an affinity for $\operatorname{TR} \beta$ in fish that is similar to that of T3 (Mendoza et al., 2013), indicating an evolutionary role for this iodothyronine as a genuine classic TH. In Wistar rats housed at thermoneutrality and placed on a high-fat diet (50\% fat), T2 $(25 \mu \mathrm{g} / 100 \mathrm{~g}$ BW $)$ induces a protein profile favoring a shift toward fast-twitch, type II skeletal muscle fibers, and a preference for glucose as fuel (Moreno et al., 2011). Under the same conditions, T2 has strong lipid lowering effects and can effectively prevent hepatic steatosis, ameliorating tissue and systemic insulin sensitivity (de Lange et al., 2011). T2, apart from binding directly to subunit Va of mitochondrial cytochrome-c oxidase, enhancing its activity (Arnold et al., 1998), acts by activating hepatic nuclear SIRT1, which deacetylates PGC-1 $\alpha$ and SREBP-1c, thus inducing the expression of genes involved in mitochondrial fatty acid oxidation, and repressing genes involved in lipogenesis, respectively, confirmed by proteomic profiling (de Lange et al., 2011). Thyroid hormones, ameliorating metabolic parameters, may improve healthy aging (see for review de Lange et al., 2013). Indeed, very recently, Padron et al. (2014) reported that T2 administration $(25,50$, and $75 \mu \mathrm{g} / 100 \mathrm{~g} \mathrm{BW})$ to aging Wistar rats reduced body- and retroperitoneal fat mass gain, increased resting metabolic rate (RMR), ameliorated glucose tolerance, did not alter heart mass and heart rate, and only lowered serum T4 and T3 levels at the two higher doses (Padron et al., 2014). A similar effect was recently observed in HFD-fed mice which showed increased heart weights only when treated with unusual very high doses of T2 (250 $\mathrm{g} / 100 \mathrm{~g} \mathrm{BW})$ (Jonas et al., 2014). Reaching a "safe" dose of T2 may thus be feasible in humans as well, which warrants further investigation.

\section{CONCLUSIONS AND PERSPECTIVES}

There has been much progress in identifying "novel" mechanisms of action of T3 and T2 (Figure 1) and TH metabolites and in developing "safe" (that is: non-thyrotoxic) TH-related compounds to reduce lipid profiles. The discovery of thyroid-related compounds which could be implied in the regulation of energy balance may thus pave the way to strategies for their use in the clinic.

\section{REFERENCES}

Angelin, B., and Rudling, M. (2010). Lipid lowering with thyroid hormone and thyromimetics. Curr. Opin. Lipidol. 21, 499-506. doi: 10.1097/MOL.0b013e3283402e9c

Araki, O., Ying, H., Zhu, X. G., Willingham, M. C., and Cheng, S. Y. (2009). Distinct dysregulation of lipid metabolism by unliganded thyroid hormone receptor isoforms. Mol. Endocrinol. 23, 308-315. doi: 10.1210/me.20 08-0311

Arnold, S., Goglia, F., and Kadenbach, B. (1998). 3,5 Diiodothyronine binds to subunit Va of cytochrome-c oxidase and abolishes the allosteric inhibition of respiration by ATP. Eur. J. Biochem. 252, 325-330. doi: 10.1046/j.14321327.1998.2520325.x

Astapova, I., and Hollenberg, A. N. (2013). The in vivo role of nuclear receptor corepressors in thyroid hormone action. Biochim. Biophys. Acta 1830, 3876-3881. doi: 10.1016/j.bbagen.2012.07.001
Astapova, I., Ramadoss, P., Costa-e-Sousa, R. H., Ye, F., Holtz, K. A., Li, Y., et al. (2014). Hepatic nuclear corepressor 1 regulates cholesterol absorption through a TRß1-governed pathway. J. Clin. Invest. 124, 1976-1986. doi: 10.1172/JCI73419

Ball, S. G., Sokolov, J., and Chin, W. W. (1997). 3,5-Diiodo-L-thyronine (T2) has selective thyromimetic effects in vivo and in vitro. J. Mol. Endocrinol. 19, 137-147.

Baumann, C. T., Maruvada, P., Hager, G. L., and Yen, P. M. (2001). Nuclear cytoplasmic shuttling by Thyroid hormone receptors. Multiple protein interactions are required for nuclear retention. J. Biol. Chem. 276, 11237-11245. doi: 10.1074/jbc.M011112200

Baxter, J. D., and Webb, P. (2009). Thyroid hormone mimetics: potential applications in atherosclerosis, obesity and type 2 diabetes. Nat. Rev. Drug Discov. 8, 308-320. doi: 10.1038/nrd2830

Berkenstam, A., Kristensen, J., Mellström, K., Carlsson, B., Malm, J., Rehnmark, S., et al. (2008). The Thyroid hormone mimetic compound KB2115 lowers plasma LDL cholesterol and stimulates bile acid synthesis without cardiac effects in humans. Proc. Natl. Acad. Sci. U.S.A. 105, 663-667. doi: 10.1073/pnas.0705286104

Bogazzi, F., Hudson, L. D., and Nikodem, V. M. (1994). A novel heterodimerization partner for Thyroid hormone receptor. Peroxisome proliferator activated receptor. J. Biol. Chem. 269, 11683-11686.

Borngraeber, S., Budny, M. J., Chiellini, G., Cunha-Lima, S. T., Togashi, M., Webb, P., et al. (2003). Ligand selectivity by seeking hydrophobicity in Thyroid hormone receptor. Proc. Natl. Acad. Sci. U.S.A. 100, 15358-15363. doi: 10.1073/pnas.2136689100

Buroker, N. E., Young, M. E., Wei, C., Serikawa, K., Ge, M., Ning, X. H., et al. (2007). The dominant negative thyroid hormone receptor beta mutant \{Delta\}337T alters PPAR \{alpha\} signaling in heart. Am. J. Physiol. Endocrinol. Metab. 292, E453-E460. doi: 10.1152/ajpendo.00267.2006

Cable, E. E., Finn, P. D., Stebbins, J. W., Hou, J., Ito, B. R., van Poelje, P., et al. (2009). Reduction of hepatic steatosis in rats and mice after treatment with a liver-targeted thyroid hormone receptor agonist. Hepatology 49, 407-417. doi: 10.1002/hep. 22572

Chang, H. C., and Guarente, L. (2014). SIRT1 and other sirtuins in metabolism. Trends Endocrinol. Metab. 25, 138-145. doi: 10.1016/j.tem.2013.12.001

Chiellini, G., Apriletti, J. W., Yoshihara, H. A., Baxter, J. D., Ribeiro, R. C., and Scanlan, T. S. (1998). A high-affinity subtype-selective agonist ligand for the thyroid hormone receptor. Chem. Biol. 5, 299-306. doi: 10.1016/S10745521(98)90168-5

Cioffi, F., Zambad, S. P., Chhipa, L., Senese, R., Busiello, R. A., Tuli, D., et al. (2010). TRC150094, a novel functional analog of iodothyronines, reduces adiposity by increasing energy expenditure and fatty acid oxidation in rats receiving a highfat diet. FASEB J. 24, 3451-3461. doi: 10.1096/fj.10-157115

Davis, P. J., Davis, F. B., and Cody, V. (2005). Membrane receptors mediating Thyroid hormone action. Trends Endocrinol. Metab. 16, 429-435. doi: 10.1016/j.tem.2005.09.007

Davis, P. J., Shih, A., Lin, H. Y., Martino, L. J., and Davis, F. B. (2000). Thyroxine promotes association of mitogen-activated protein kinase and nuclear thyroid hormone receptor (TR) and causes serine phosphorylation of TR. J. Biol. Chem. 275, 38032-38039. doi: 10.1074/jbc.M002560200

de Lange, P., Cioffi, F., Senese, R., Moreno, M., Lombardi, A., Silvestri, E., et al. (2011). Nonthyrotoxic prevention of diet-induced insulin resistance by 3,5 diiodo-L-thyronine in rats. Diabetes 60, 2730-2739. doi: 10.2337/db11-0207

de Lange, P., Cioffi, F., Silvestri, E., Moreno, M., Goglia, F., and Lanni, A. (2013). (Healthy) ageing: focus on iodothyronines. Int. J. Mol. Sci. 14, 13873-13892. doi: 10.3390/ijms140713873

de Lange, P., Feola, A., Ragni, M., Senese, R., Moreno, M., Lombardi, A., et al. (2007). Differential 3,5,3'-triiodothyronine-mediated regulation of uncoupling protein 3 transcription: role of Fatty acids. Endocrinology 148, 4064-4072. doi: 10.1210/en.2007-0206

de Lange, P., Senese, R., Cioffi, F., Moreno, M., Lombardi, A., Silvestri, E., et al. (2008). Rapid activation by 3,5,3'-L-triiodothyronine of adenosine $5^{\prime}$ monophosphate-activated protein kinase/acetyl-coenzyme a carboxylase and akt/protein kinase B signaling pathways: relation to changes in fuel metabolism and myosin heavy-chain protein content in rat gastrocnemius muscle in vivo. Endocrinology 149, 6462-6470. doi: 10.1210/en.2008-0202

Erion, M. D., Cable, E. E., Ito, B. R., Jiang, H., Fujitaki, J. M., Finn, P. D., et al. (2007). Targeting thyroid hormone receptor-beta agonists to the liver reduces cholesterol and triglycerides and improves the therapeutic index. 
Proc. Natl. Acad. Sci. U.S.A. 104, 15490-15495. doi: 10.1073/pnas.07027 59104

Forman, B. M., Casanova, J., Raaka, B. M., Ghysdael, J., and Samuels, H. H. (1992). Half-site spacing and orientation determines whether thyroid hormone and retinoic acid receptors and related factors bind to DNA response elements as monomers, homodimers, or heterodimers. Mol. Endocrinol. 6, 429-442.

Fujitaki, J. M., Cable, E. E., Ito, B. R., Zhang, B. H., Hou, J., Yang, C., et al. (2008). Preclinical pharmacokinetics of a HepDirect prodrug of a novel phosphonate-containing thyroid hormone receptor agonist. Drug Metab. Dispos. 36, 2393-2403. doi: 10.1124/dmd.108.021642

Gloss, B., Trost, S., Bluhm, W., Swanson, E., Clark, R., and Winkfein, R. (2001). Cardiac ion channel expression and contractile function in mice with deletion of thyroid hormone receptor alpha or beta. Endocrinology 142, 544-550. doi: 10.1210/en.142.2.544

Goldberg, I. J., Huang, L. S., Huggins, L. A., Yu, S., Nagareddy, P. R., Scanlan, T. S., et al. (2012). Thyroid hormone reduces cholesterol via a non-LDL receptormediated pathway. Endocrinology 153, 5143-5149. doi: 10.1210/en.2012-1572

Grover, G. J., Egan, D. M., Sleph, P. G., Beehler, B. C., Chiellini, G., Nguyen, N. H., et al. (2004). Effects of the thyroid hormone receptor agonist GC-1 on metabolic rate and cholesterol in rats and primates: selective actions relative to 3,5,3'triiodo-L-thyronine. Endocrinology 145, 1656-1661. doi: 10.1210/en.2003-0973

Grover, G. J., Mellstrom, K., and Malm, J. (2005). Development of the thyroid hormone receptor beta-subtype agonist KB-141: a strategy for body weight reduction and lipid lowering with minimal cardiac side effects. Cardiovasc. Drug Rev. 23, 133-148. doi: 10.1111/j.1527-3466.2005.tb00161.x

Grover, G. J., Mellström, K., Ye, L., Malm, J., Li, Y. L., Bladh, L. G., et al. (2003). Selective thyroid hormone receptor-beta activation: a strategy for reduction of weight, cholesterol, and lipoprotein (a) with reduced cardiovascular liability. Proc. Natl. Acad. Sci. U.S.A. 100, 10067-10072. doi: 10.1073/pnas.16337 37100

Gullberg, H., Rudling, M., Forrest, D., Angelin, B., and Vennström, B. (2000). Thyroid hormone receptor beta-deficient mice show complete loss of the normal cholesterol 7alpha-hydroxylase (CYP7A) response to TH but display enhanced resistance to dietary cholesterol. Mol. Endocrinol. 14, 1739-1749. doi: 10.1210/me.14.11.1739

Gullberg, H., Rudling, M., Salto, C., Forrest, D., Angelin, B., and Vennstrom, B. (2002). Requirement for thyroid hormone receptor $\beta$ in T3 regulation of cholesterol metabolism in mice. Mol. Endocrinol. 16, 1767-1777. doi: 10.1210/me.2002-0009

Hardie, D. G., Ross, F. A., and Hawley, S. A. (2012). AMP-activated protein kinase: a target for drugs both ancient and modern. Chem. Biol. 19, 1222-1236. doi: 10.1016/j.chembiol.2012.08.019

Hoefig, C. S., Köhrle, J., Brabant, G., Dixit, K., Yap, B., Strasburger, C. J., et al. (2011). Evidence for extrathyroidal formation of 3-iodothyronamine in humans as provided by a novel monoclonal antibody-based chemiluminecent serum immunoassay. J. Clin. Endocrinol. Metab. 96, 1864-1872. doi: 10.1210/jc.20102680

Ichikawa, K., Miyamoto, T., Kakizawa, T., Suzuki, S., Kaneko, A., Mori, J., et al. (2000). Mechanism of liver-selective thyromimetic activity of SK\&F L-94901: evidence for the presence of a cell-type-specific nuclear iodothyronine transport process. J. Endocrinol. 165, 391-397. doi: 10.1677/joe.0.1650391

Irrcher, I., Walkinshaw, D. R., Sheehan, T. E., and Hood, D. A. (2008). Thyroid hormone (T3) rapidly activates $\mathrm{p} 38$ and AMPK in skeletal muscle in vivo. J. Appl. Physiol. 104, 178-185. doi: 10.1152/japplphysiol.00643.2007

Johansson, L., Rudling, M., Scanlan, T. S., Lundåsen, T., Webb, P., Baxter, J., et al. (2005). Selective thyroid receptor modulation by GC-1 reduces serum lipids and stimulates steps of reverse cholesterol transport in euthyroid mice. Proc. Natl. Acad. Sci. U.S.A. 102, 10297-10302. doi: 10.1073/pnas.0504379102

Jonas, W., Lietzow, J., Wohlgemuth, F., Hoefig, C. S., Wiedmer, P., Schweizer, U., et al. (2014). 3,5-Diiodo-L-thyronine (3,5-T2) exerts thyromimetic effects on hypothalamus-pituitary-thyroid axis, body composition, and energy metabolism in male dietinduced obese mice. Endocrinology. doi: 10.1210/en.2014-1604. [Epub ahead of print].

Jornayvaz, F. R., Lee, H. Y., Jurczak, M. J., Alves, T. C., Guebre-Egziabher, F., Guigni, B. A., et al. (2012). Thyroid hormone receptor- $\alpha$ gene knockout mice are protected from diet-induced hepatic insulin resistance. Endocrinology 153, 583-591. doi: 10.1210/en.2011-1793

Lin, J. Z., Martagón, A. J., Hsueh, W. A., Baxter, J. D., Gustafsson, J. Å., Webb, P., et al. (2012). Thyroid hormone receptor agonists reduce serum cholesterol independent of the LDL receptor. Endocrinology 153, 6136-6144. doi: 10.1210/en.2011-2081

Liu, Y. Y., Heymann, R. S., Moatamed, F., Schultz, J. J., Sobel, D., and Brent, G. A. (2007). A mutant thyroid hormone receptor alpha antagonizes peroxisome proliferator-activated receptor alpha signaling in vivo and impairs fatty acid oxidation. Endocrinology 148, 1206-1211. doi: 10.1210/en.2006-0836

Lombardi, A., de Lange, P., Silvestri, E., Busiello, R. A., Lanni, A., Goglia, F., et al. (2009). 3,5-Diiodo-L-thyronine rapidly enhances mitochondrial fatty acid oxidation rate and thermogenesis in rat skeletal muscle: AMP-activated protein kinase involvement. Am. J. Physiol. Endocrinol. Metab. 296, E497-E502. doi: 10.1152/ajpendo.90642.2008

Manni, M. E., De Siena, G., Saba, A., Marchini, M., Dicembrini, I., Bigagli, E., et al. (2012). 3-Iodothyronamine: a modulator of the hypothalamus-pancreasthyroid axes in mice. Br. J. Pharmcol. 166, 650-658. doi: 10.1111/j.14765381.2011.01823.x

Mendoza, A., Navarrete-Ramírez, P., Hernández-Puga, G., Villalobos, P., Holzer, G., Renaud, J. P., et al. (2013). 3,5-T2 is an alternative ligand for the Thyroid hormone receptor $\beta 1$. Endocrinology 154, 2948-2958. doi: 10.1210/en.2013-1030

Moeller, L. C., Cao, X., Dumitrescu, A. M., Seo, H., and Refetoff, S. (2006). Thyroid hormone mediated changes in gene expression can be initiated by cytosolic action of the TH receptor b through the phosphatidylinositol 3-kinase pathway. Nucl. Recept. Signal. 4:e020. doi: 10.1621/nrs.04020

Moreno, M., de Lange, P., Lombardi, A., Silvestri, E., Lanni, A., and Goglia, F. (2008). Metabolic effects of TH derivatives. Thyroid 18, 239-253. doi: 10.1089/thy.2007.0248

Moreno, M., Silvestri, E., De Matteis, R., de Lange, P., Lombardi, A., Glinni, D., et al. (2011). 3,5-Diiodo-L-thyronine prevents high-fat-diet-induced insulin resistance in rat skeletal muscle through metabolic and structural adaptations. FASEB J. 25, 3312-3324. doi: 10.1096/fj.11-181982

Mullur, R., Liu, Y. Y., and Brent, G. A. (2014). Thyroid hormone regulation of metabolism. Physiol. Rev. 94, 355-382. doi: 10.1152/physrev.00030.2013

Oetting, A., and Yen, P. (2007). New insights into thyroid hormone action. Best Pract. Res. Clin. Endocrinol. Metab. 21, 193-208. doi: 10.1016/j.beem.2007.04.004

Padron, A. S., Neto, R. A., Pantaleão, T. U., de Souza dos Santos, M. C., Araujo, R. L., de Andrade, B. M., et al. (2014). Administration of 3,5-diiodothyronine $(3,5-\mathrm{T} 2)$ causes central hypothyroidism and stimulates thyroid-sensitive tissues. J. Endocrinol. 221, 415-427. doi: 10.1530/JOE-13-0502

Plow, E. F., Haas, T. A., Zhang, L., Loftus, J., and Smith, J. W. (2000). Ligand binding to integrins. J. Biol. Chem. 275, 21785-21788. doi: 10.1074/jbc.R000003200

Pramfalk, C., Pedrelli, M., and Parini, P. (2011). Role of thyroid receptor $\beta$ in lipid metabolism. Biochim. Biophys. Acta 1812, 929-937. doi: 10.1016/j.bbadis.2010.12.019

Saba, A., Chiellini, G., Frascarelli, S., Marchini, M., Ghelardoni, S., Raffaelli, A., et al. (2010). Tissue distribution and cardiac metabolism of 3-iodothyronamine. Endocrinology 151, 5063-5073. doi: 10.1210/en.2010-0491

Senese, R., Cioffi, F., de Lange, P., Goglia, F., and Lanni, A. (2014). Thyroid: biological actions of "nonclassical" THs. J. Endocrinol. 221, R1-R12. doi: 10.1530/JOE-13-0573

Shang, G., Gao, P., Zhao, Z., Chen, Q., Jiang, T., Zhang, N., et al. (2013). 3,5-Diiodo-l-thyronine ameliorates diabetic nephropathy in streptozotocininduced diabetic rats. Biochim. Biophys. Acta 1832, 674-684. doi: 10.1016/j.bbadis.2013.01.023

Shoemaker, T. J., Kono, T., Mariash, C. N., and Evans-Molina, C. (2012). Thyroid hormone analogues for the treatment of metabolic disorders: new potential for unmet clinical needs? Endocr. Pract. 18, 954-964. doi: 10.4158/EP12086.RA

Singh, B. K., Sinha, R. A., Zhou, J., Xie, S. Y., You, S. H., Gauthier, K., et al. (2013). FoxO1 deacetylation regulates Thyrod hormone-induced transcription of key hepatic gluconeogenic genes. J. Biol. Chem. 288, 30365-30372. doi: 10.1074/jbc.M113.504845

Sjouke, B., Langslet, G., Ceska, R., Nicholls, S. J., Nissen, S. E., Ohlander, M., et al. (2014). Eprotirome in patients with familial hypercholesterolaemia (the AKKA trial): a randomised, double-blind, placebo-controlled phase 3 study. Lancet Diabetes Endocrinol. 2, 455-463. doi: 10.1016/S2213-8587(14)70006-3

Suh, J. H., Sieglaff, D. H., Zhang, A., Xia, X., Cvoro, A., Winnier, G. E., et al. (2013). SIRT1 is a Direct Coactivator of Thyroid Hormone Receptor b1 with GeneSpecific Actions. PLoS ONE 8:e70097. doi: 10.1371/journal.pone.0070097

Tancevski, I., Demetz, E., Eller, P., Duwensee, K., Hoefer, J., Heim, C., et al. (2010). The liver-selective thyromimetic T-0681 influences reverse cholesterol 
transport and atherosclerosis development in mice. PLOS ONE 5:e8722. doi: 10.1371/journal.pone.0008722

Tancevski, I., Wehinger, A., Demetz, E., Hoefer, J., Eller, P., Huber, E., et al. (2009). The thyromimetic T-0681 protects from atherosclerosis. J. Lipid Res. 50, 938-944. doi: 10.1194/jlr.M800553-JLR200

Taylor, A. H., Stephan, Z. F., Steele, R. E., and Wong, N. C. (1997). Beneficial effects of a novel thyromimetic on lipoprotein metabolism. Mol. Pharmacol. 52, 542-547.

Thakran, S., Sharma, P., Attia, R. R., Hori, R. T., Deng, X., Elam, M. B., et al. (2013). Role of sirtuin 1 in the regulation of hepatic gene expression by Thyroid hormone. J. Biol. Chem. 288, 807-818. doi: 10.1074/jbc.M112.437970

Underwood, A. H., Emmett, J. C., Ellis, D., Flynn, S. B., Leeson, P. D., Benson, G. M., et al. (1986). A thyromimetic that decreases plasma cholesterol levels without increasing cardiac activity. Nature 324, 425-429.

Vatner, D. F., Weismann, D., Beddow, S., Kumashiro, N., Erion, D. M., Liao, X.-H., et al. (2012). Thyroid hormone receptor $\beta$ agonists prevent hepatic steatosis in fat-fed rats but impair insulin sensitivity via discrete pathways. Am. J. Physiol. Endocrinol. Metab. 305, E89-E100. doi: 10.1152/ajpendo.00573.2012

Webb, P. (2004). Selective activators of thyroid hormone receptors. Expert Opin. Investig. Drugs 13, 489-500. doi: 10.1517/13543784.13.5.489

Weiss, R. E., Korcarz, C., Chassande, O., Cua, K., Sadow, P. M., Koo, E., et al. (2002). Thyroid hormone and cardiac function in mice deficient in thyroid hormone receptor-alpha or -beta: an echocardiographic study. Am. J. Physiol. Endocrinol. Metab. 283, E428-E435. doi: 10.1152/ajpendo.00019.2002

Wikström, L., Johansson, C., Saltó, C., Barlow, C., Campos Barros, A., Baas, F., et al. (1998). Abnormal heart rate and body temperature in mice lacking thyroid hormone receptor alpha 1. EMBO J. 17, 455-461.
Williams, G. R. (2000). Cloning and characterization of two novel thyroid hormone receptor $\beta$ isoforms. Mol. Cell. Biol. 20, 8329-8342. doi: 10.1128/MCB.20.22.8329-8342.2000

Wrutniak-Cabello, C., Casas, F., and Cabello, G. (2001). Thyroid hormone action in mitochondria. J. Mol. Endocrinol. 26, 67-77. doi: 10.1677/jme.0. 0260067

Zucchi, R., Chiellini, G., Scanlan, T. S., and Grandy, D. K. (2006). Trace amineassociated receptors and their ligands. Br. J. Pharmacol. 149, 967-978. doi: 10.1038/sj.bjp.0706948

Conflict of Interest Statement: The authors declare that the research was conducted in the absence of any commercial or financial relationships that could be construed as a potential conflict of interest.

Received: 02 October 2014; accepted: 20 November 2014; published online: 05 December 2014.

Citation: Senese R, Lasala P, Leanza C and de Lange P (2014) New avenues for regulation of lipid metabolism by thyroid hormones and analogs. Front. Physiol. 5:475. doi: 10.3389/fphys.2014.00475

This article was submitted to Integrative Physiology, a section of the journal Frontiers in Physiology.

Copyright (C) 2014 Senese, Lasala, Leanza and de Lange. This is an open-access article distributed under the terms of the Creative Commons Attribution License (CC BY). The use, distribution or reproduction in other forums is permitted, provided the original author(s) or licensor are credited and that the original publication in this journal is cited, in accordance with accepted academic practice. No use, distribution or reproduction is permitted which does not comply with these terms. 